\title{
Conducting qualitative research in audiology: A tutorial
}

Line V Knudsen, Ariane Laplante-Levesque, Lesley Jones, Jill E Preminger, Claus Nielsen, Thomas Lunner, Louise Hickson, Graham Naylor and Sophia E Kramer

\section{Linköping University Post Print}

N.B.: When citing this work, cite the original article.

Original Publication:

Line V Knudsen, Ariane Laplante-Levesque, Lesley Jones, Jill E Preminger, Claus Nielsen, Thomas Lunner, Louise Hickson, Graham Naylor and Sophia E Kramer, Conducting qualitative research in audiology: A tutorial, 2012, International Journal of Audiology, (51), 2, 83-92.

http://dx.doi.org/10.3109/14992027.2011.606283

Copyright: Informa Healthcare http://informahealthcare.com/

Postprint available at: Linköping University Electronic Press http://urn.kb.se/resolve?urn=urn:nbn:se:liu:diva-74840 
Manuscript accepted on 2011-07-14 for publication in International Journal of

\section{Audiology}

\section{Reference as:}

Knudsen, L.V, Laplante-Lévesque, A., Jones, L. Preminger, J.E., Nielsen, C., Lunner, T., Hickson, L., Naylor, G., \& Kramer, S.E. in press. Conducting qualitative research in audiology: A tutorial. International Journal of Audiology.

Title

Conducting qualitative research in audiology: A tutorial

\section{Authors and institutional affiliations}

Knudsen, Line V. ${ }^{a}$

Laplante-Lévesque, Ariane ${ }^{a, b}$

Jones, Lesley ${ }^{c}$

Preminger, Jill E. ${ }^{d}$

Nielsen, Claus ${ }^{a}$

Lunner, Thomas,

Hickson, Louise ${ }^{b}$

Naylor, Graham ${ }^{a}$

Kramer, Sophia E. ${ }^{f}$

${ }^{a}$ Eriksholm Research Centre

Oticon A/S

243 Kongevejen

DK-3070 Snekkersten

Denmark

${ }^{\mathrm{b}}$ Communication Disability Centre

Division of Audiology

School of Health and Rehabilitation Sciences

The University of Queensland

Brisbane, Queensland 4072

Australia 
${ }^{\mathrm{C}}$ Hull York Medical School

University of York

YO 10 5DD York

United Kingdom

dUniversity of Louisville

School of Medicine, Myers Hall

Louisville, KY 40292

USA

e Linnaeus Centre HEAD

The Swedish Institute for Disability Research

Department of Behavioural Sciences and Learning, Linköping University

SE-581 83 Linköping

Sweden

${ }^{f}$ VU University medical center

Dept. of ENT/Audiology, EMGO Institute

P.O. Box 7057

1007 MB Amsterdam

The Netherlands

\section{Corresponding author}

Ariane Laplante-Lévesque

Eriksholm Research Centre

Oticon A/S

243 Kongevejen

DK-3070 Snekkersten

Denmark

arl@oticon.dk

\section{Keywords}

Qualitative, Audiologic rehabilitation, Client perspectives, International,

Interdisciplinary 


\section{Abstract}

Objective: Qualitative research methodologies are being used more frequently in audiology as it allows for a better understanding of the perspectives of people with hearing impairment. This article describes why and how international interdisciplinary qualitative research can be conducted. Design: A literature review and our recent experience with the conduction of an international interdisciplinary qualitative study in audiology informed this article. Results: We describe some available qualitative methods for sampling, data collection, and analysis and we discuss the rationale for choosing particular methods. The focus is on four approaches which have all previously been applied to audiologic research: grounded theory, interpretative phenomenological analysis, conversational analysis, and qualitative content analysis. Conclusions: This article provides a review of methodological issues useful for those designing qualitative research projects in audiology or needing assistance in the interpretation of qualitative literature. 
To date, research in hearing-aid rehabilitation has mainly focused on the quantitative effects of demographic, personal, technological, and dispensing factors on hearingaid outcomes (such as help-seeking, hearing-aid use, satisfaction, and quality of life). Whereas previous work yielded valuable information, it has been emphasized that research in audiology is still struggling to identify factors related to hearing-aid uptake, use, and satisfaction that really make a difference (Vestergaard Knudsen et al, 2010). Qualitative reports have been conducted to provide much-needed knowledge about the effects of interpersonal and psychosocial factors on hearing disability, help-seeking, and rehabilitation (e.g., Hallberg \& Carlsson, 1991; Hétu et al, 1988; Laplante-Lévesque et al, 2010; Lockey et al, 2010; Scarinci et al, 2008; Southall et al, 2010). Qualitative research has been widely used in other fields of health. For example, the publications Qualitative Health Research (www.qhr.sagepub.com) and International Journal of Qualitative Studies on Health and Well-being (www.ijghw.net) focus on such research.

By often using an open-ended approach, qualitative research has the ability to generate new information that may otherwise have been overlooked. Focusing on the experiences and perceptions of people living with a health condition, qualitative methods recognize the uniqueness of the human experience (Bradley et al, 2007; Lincoln, 1992) as it is influenced by biological as well as psychological and sociological aspects (World Health Organization, 2001). Gaining new knowledge concerning the experiences of living with a specific health condition, seeking help, 
and engaging in rehabilitation may contribute to improvements in the delivery of health care.

Aim

This article provides a review of methodological issues useful for those designing qualitative research projects in audiology or needing assistance in the interpretation of qualitative literature. Throughout the article, we describe and discuss four alternative approaches to qualitative methods: grounded theory, interpretative phenomenological analysis, conversational analysis, and qualitative content analysis. The purpose is to contribute to audiology research with insights arising from our experience conducting an interdisciplinary qualitative study and arising from the literature. The results of a multi-site, international qualitative study we conducted are reported in a companion article (Laplante-Lévesque et al, in press).

\section{Qualitative research}

Qualitative research is generally based in a scientific philosophy informed by interpretivism, a paradigm in which it is assumed that reality can be interpreted in various ways and that knowledge and understanding are dependent on context and individual experience (Bryman, 2008; Graneheim \& Lundman, 2004). Many qualitative approaches also imply that humans construct social reality (Berger \& Luckman, 1966) and therefore are the channels to gain knowledge about social aspects of human life. Qualitative research thus attempts to understand, gain insight, and describe human meaning making, behaviors, and beliefs. Qualitative knowledge 
is based on close examinations of spoken or written words, pictures or moving images regarding or created by the research participants. Qualitative analysis often illustrates multiple aspects of human actions and demonstrates paradoxes and contradictions. Many qualitative research schools acknowledge that meaning making also takes place during the research. In this view, the researcher and the participant interact by their engagement in a dialogue, either directly via interview, or more indirectly when the researcher observes, interprets, and analyses the actions of the subject. This dialogue creates meaning and therefore influences social reality.

Qualitative research can be informed by data-driven inductive or theory-driven deductive approaches. The results of inductive qualitative research range from descriptive accounts of specific aspects of human actions to more or less abstracted theories about human behavior and social structures. In contrast, the results of deductive qualitative research confirm, deny, or expand an already established social, cultural or psychological theory (Bryman, 2008).

\section{Qualitative or quantitative approaches}

Human behavior, perspectives, and meaning making of people also can be studied using quantitative methods. Taking such an approach, the aim of study should be to generate knowledge about whether an already identified type of meaning making is associated with some relevant outcome measures (Inui, 1996). For instance, how people make meaning of a trauma relates to negative outcomes such as posttraumatic stress can be studied with quantitative research (Berntsen \& Rubin, 2006). 
The quantitative study of human meaning making typically tests hypothetical or theoretical causal relations (Dzurec \& Abraham, 1993). The hypothesis informs the formulation of standardized questions that can generate comparable and validated answers within a large participant sample.

Thus there are obvious differences between a quantitative and a qualitative approach for researching social phenomena (Bryman, 2008; Carr, 1994; Mahoney \& Goertz, 2006). For a summary of those differences see Table 1.

<Insert Table 1 about here.>

In addition, the criteria applied when ensuring and evaluating the quality of research also are different between these two scientific paradigms. The results of good quantitative research are valid and reliable (Bentler \& Kramer, 2000; Bryman, 2008; Golafshani, 2003). Validity means that the study design should be suitable to measure what it is set out to assess. Reliability means that results of a study (e.g., a survey) should not fluctuate over short periods of time or when conducted among other populations comparable to the sampled study group. When a study is valid and reliable, the results may be generalized to a target population.

Within qualitative research trustworthiness (Bryman, 2008; Golafshani, 2003; Lincoln \& Guba, 1985) has been suggested as an equivalent to validity and reliability in quantitative research. Trustworthiness is a criterion that contains credibility, 
transferability, and dependability. Credibility is (as internal validity in quantitative research) concerned with the quality of the methodology used to conduct and evaluate a study. High credibility is achieved by choosing methods consistent with the research topic and by using triangulation throughout the study process. Triangulation means including multiple data sources and/or methodological approaches to study the topic chosen as well as including several voices (e.g., researchers as well as study participants) in the analysis of the data material (Barry et al, 1999; Miles \& Huberman, 1994). Transferability (as external validity in quantitative research) ensures that the study provides rich contextual information to give the reader enough detail to determine whether the conclusions of the study are unique or can have relevance to similar social phenomena (Bryman, 2008). The third criterion, dependability (as reliability is in quantitative research), ensures that consistency in the treatment of data is obtained and kept transparent. This means, for qualitative research, that the study steps, decisions, and considerations are documented, in a way that makes the study process clear and easily understood. Generalizability is not a goal of qualitative research, rather the goal is to generate new perspectives and theories which may later be verified with quantitative research.

Although many attempts have been made to distance quantitative and qualitative research, it is clear that the two approaches also have commonalities. In general, the thoughtful choice and definition of research question, sampling strategy, data collection, analysis methods, and format of documentation has a vital influence on 
the output of both the research approaches (Côté \& Turgeon, 2005; Dzurec \& Abraham, 1993).

Some research questions can best be answered by mixed methods, where quantitative and qualitative methods are used (Bryman, 2008; Carr, 1994; Creswell, 2003). This can be done in different ways. For example, a preliminary explorative study can inform the design of a questionnaire for survey (de Andrade \& Ross, 2005). Alternatively, a qualitative study can help interpret and elaborate the results of a quantitative study (Poortinga et al, 2004).

\section{Theoretical, methodological, and practical issues when conducting qualitative research}

In the following tutorial, we present different practical, methodological as well as theoretical issues that should be taken into consideration when conducting or interpreting qualitative research within audiology. We have chosen to focus on four different theoretical methodological approaches to qualitative research previously used in audiology: grounded theory, interpretative phenomenological analysis, conversational analysis, and qualitative content analysis. We have chosen those four approaches as they have so far been the qualitative approaches most frequently used within audiology. They all are approaches suitable for pragmatic and explorative qualitative studies on the perspectives of people with hearing impairment. For other types of health research, other approaches such as case studies, ethnographic studies, or studies framed by critical social theory can be more 
suitable approaches. The approaches chosen for this tutorial are similar in the steps of sampling, recruitment and data collection. However the approaches are different in the step of data analysis. Therefore, the different approaches are discussed together in this manuscript, until the section on data analysis. Nonetheless in the sampling, recruitment, and data collection sections the practical or methodological issues specific to the approaches are mentioned.

\section{Four theoretical/methodological approaches}

Grounded theory (Charmaz, 2000; Charmaz \& Bryant, 2010; Miles \& Huberman, 1994; Strauss \& Corbin, 1998) is a systematic method developed within sociology. Coding, constant data categorization, and comparison, interpretation, and theorization are used to develop new theory from data without presupposed hypotheses. Grounded theory is a qualitative method commonly used in audiology (e.g., Hallberg \& Carlsson, 1991; Laplante-Lévesque et al, 2006; Wallhagen, 2010). For instance, Wallhagen (2010) conducted interviews with dyads where one partner had a hearing impairment over a period of one year. Three experiences related to stigma were found by an ongoing process of interviewing, analysing and comparing data, and refining concepts. These were named alterations in selfperception, ageism, and vanity. In this study stigma was hypothesized as a significant factor explaining why people with hearing impairment rejected the use of hearing aids. However, no a priori hypotheses as to what identified stigma and what other experiences stigma was related to had been formulated. 
Interpretative phenomenological analysis (Lopez \& Willis, 2004; Smith et al, 1999;

Smith et al, 2009) is a psychological qualitative research method with strong influences from phenomenological and hermeneutic philosophy. Interpretative phenomenology yields an understanding of how humans experience, make sense of, and relate to specific phenomena. The method has a bottom-up approach taking its starting point in the close analysis of bodily and linguistic experiences of participants to define common features or essences of lived experience. A later step in the analysis can include linking the experiences of a specific phenomenon to the wider social, cultural, and political context. Interpretative phenomenology has been widely used in health research and has also been applied to research in audiology (e.g., Hétu et al, 1988; Lockey et al, 2010). Lockey and colleagues (2010) analysed biographic-narrative-interviews with older women with hearing impairment by using a interpretative phenomenological approach. The study revealed that the women found that they could participate meaningfully in social life both with and without hearing aids, depending on the nature of the activity they were engaged in. Also, barriers to participation not only depended on the degree of successfull hearing aid use. By taking the experiences of the interviewed participants into account it was thus found that barriers and facilitators to participation were less influenced by the amount of hearing aid use than expected.

Qualitative content analysis is an analysis method used in many disciplines such as psychology, sociology, and ethnography. It has also been used extensively in health research, for instance in nursing (Elo \& Kyngäs, 2008; Graneheim \& Lundman, 2004; 
Hsieh \& Shannon, 2005). Content analysis was developed as a quantitative discipline serving to get an overview of the semantic content of texts or large amounts of transcribed interview data. Within the last decades, qualitative content analysis has developed to become a frequently used analysis method within, for instance, qualitative health research. Qualitative content analysis can be conducted with various depths of interpretation and be more or less directed or summative. Often the research question and the data itself drive the analysis process rather than presupposed theories or perspectives. This approach is generally used in descriptive and naturalistic qualitative research.

Qualitative content analysis primarily deals with categorisation of manifest content (i.e., what the text says) and searches to give a descriptive overview of a data material. Qualitative content analysis also includes more interpretative thematic analysis (Braun \& Clarke, 2006; Graneheim \& Lundman, 2004; Ryan \& Bernard, 2003) based on data across categories and deriving from the underlying meanings of the latent content of the data. A theme is less concrete than a category and where categories often answer questions of what, themes answer questions of why and how (Morse, 2008). Within audiology, Laplante-Lévesque and colleagues (LaplanteLévesque et al., 2010) used qualitative content analysis to describe the various factors that influenced the decision making of adults with hearing impairment . These participants were given four options in a process of shared decision making and the qualitative content analysis revealed that reasons to choose or not choose 
hearing aid rehabilitation were informed by seven factors, ranging from financial costs to perceiving the hearing aid use as a preventive and interim solution.

Conversational analysis (Sacks, 1995) studies linguistic actions in detail and therefore has a narrower methodological focus than the other approaches presented in this tutorial. This approach has been used in psychology, sociology, ethnography, linguistics, and speechpathology. Conversation analysis describes patterns of social life by close analysis of naturally occurring conversations. The analysis can have a descriptive and naturalist character to portray general patterns of language use and interactions in conversation. Alternatively, it can have a more contextual and interpretative character, for instance to portray how cultural and political discourses are performed in verbal communication. Within audiology Lind and colleagues ( Lind et al, 2006) conducted a pragmatic conversational analysis when studying the conversation repairs between an adult bilateral cochlear implantee and his wife. An initial quantitative analysis of turn takings had showed no difference in the numbers of turns taken to solve communication breakdown using either general or specific repair requests. However, when analysed qualitatively, patterns in the conversations were found to show that the immediate attempt to repair a miscommunicated portion of talk had the strongest effect compared to the later attempt to repair the miscommunication 
In qualitative research purposive sampling is used to recruit participants for whom the research topic is relevant (Creswell, 2002). Purposive sampling can range from selecting participants because of very specific circumstances or experiences (e.g., spouses of older people with hearing impairment or people who have experienced discrimination because of their hearing disability) to targeting participants with specific demographic characteristics (e.g., with regards to age, gender, or socioeconomic background; Sandelowski, 1995).

Within purposive sampling it is possible to take different directions according to the research strategy and aim. Maximum variation sampling strives to encompass heterogeneity in the sample, for example with regards to age, gender, educational level, employment, ethnicity, or any other potentially influential characteristic. Maximum variation sampling is a suitable sampling strategy when the goal is to gather common perspectives amongst people for whom the topic studied is relevant (Sandelowski, 2000). On the other hand, if commonalities within a very specific group are of interest, then homogeneous sampling should be used. When comparing the perspectives of different groups of people, stratified purposeful sampling or deviant case sampling can be relevant. This recruitment method gathers people with extraordinary or differentiated experiences of the phenomenon studied. Sampling also can be informed by theoretical research interests (Bradley et al, 2007; Strauss \& Corbin, 1998) and participants are then included on the basis of their ability to shed light on issues related to a specific concept. This approach to purposive sampling is typical of more theory-driven or theory-developing qualitative studies. Additional 
types of sampling strategies also can be used in qualitative research and the reader is referred toMiles \& Huberman (1994) and Patton ( 2002) for further reading.

Within the four different approaches (grounded theory, interpretative phenomenological analysis, qualitative content analysis, and conversation analysis) to qualitative research described in this article, sampling methods can vary according to the research aim. Furthermore, sampling techniques can change throughout the recruitment process of a qualitative study. For instance, maximum variation sampling in the beginning of the recruitment period could be followed by a more theoretically-informed sampling towards the end of the recruitment. This is often seen in grounded theory studies (Miles \& Huberman, 1994).

In qualitative research, the participant characteristics that give rise to information redundancy in the data are usually uncovered during data collection and preliminary analysis. Therefore, an ongoing monitoring of the sample composition during data collection and preliminary analysis is useful to facilitate purposeful sampling. For instance, if younger adult participants raise issues that differ from those of their older peers (irrespectively of their other characteristics), then age could become a suitable variable to consider in purposive sampling. Sampling should always be carefully monitored and documented in qualitative research.

The conditions under which participant selection takes place also should be considered. When purposefully reaching participants for qualitative health research 
it may be convenient to recruit through relevant clinical settings. However, if a health professional is to identify potential participants, a bias could occur. Health professionals might, inadvertently or not, approach participants they consider more suitable for research. Recruiting from the general population, for example with adverts in papers, increases the chances that a wide array of potential participants are reached. Snowballing is another recruitment alternative by which one participant leads to the next (Bryman, 2008; Morse, 1995). It requires asking participants to recommend family, friends, or acquaintances that could help fulfill the research aim. This method has the disadvantage of sometimes recruiting a sample from a selected part of the general population (e.g., participants from the same ethnic group). Since all recruitment strategies have potential pitfalls, a good solution is to reach participants through a variety of recruitment sources.

Potential participants can be screened during the recruitment process in order to obtain a suitable sample. Keeping a record of the eligibility and profile of all potential participants can be helpful. When conducting a multi-site study with many researchers involved in the recruitment process, a central sampling matrix should be updated and monitored by a single member of the research team who approves potential participants according to their ability to achieve suitable sampling. Sampling should occur until saturation is reached. Saturation is described in a later section of this article. 


\section{Data collection}

Possible methods of data collection in qualitative research include interviews

(DiCicco-Bloom \& Crabtree, 2006), research observations in the field (Atkinson \& Hammersley, 1994), and collection of participants' experiences in the form of documents (Collier \& Collier, 1986; Hodder, 2000). An interview can take different forms such as an individual semi-structured interviewing (Kvale, 1996), a focus group (Krueger, 1988; Morgan, 1996), or a biographic-narrative interview (Wengraf, 2001). Semi-structured interviews are most commonly used in audiology (e.g., Hallberg \& Carlsson, 1991; Laplante-Lévesque et al, 2010; Scarinci et al, 2008; Southall et al, 2010) and will therefore be described below. The articles referenced above as well as qualitative research textbooks (Bryman, 2008; Denzin \& Lincoln, 2005; Patton, 2002) describe some of the other types of qualitative data collection in further details.

Semi-structured interviews (Kvale, 1996; Starks \& Brown Trinidad, 2007) lie between unstructured interviews where no specific questions but rather an area of interest is defined and structured interviews where all questions and maybe also options for answers are defined (i.e., questionnaires). In semi-structured interviews the researcher asks participants to give accounts of their experiences of the phenomenon under study. The interview evolves as a dialogue between the study participant and the interviewer. Such approach generates open and broad interview topics and allows the participants to tell their own stories. 
An interview guide or topic guide should be developed for a semi-structured openended interview. An interview guide is more directive and structured than a topic guide. The research aims should inform the guide. Having a broad topic, such as hearing aid rehabilitation, in focus it could be suitable to open the interview with an open question such as "Tell me the story of your hearing..." This would allow participants to elaborate on the concepts which they perceive as meaningful for the topic. During the interview, probes can be given to make sure that specific aspects are covered. If, for instance, thoughts and feelings of the participants are relevant to the research aim, then such should be addressed in the topic or interview guide. Topic or interview guides are often published in qualitative reports (e.g., LaplanteLévesque et al, in press; Southall et al, 2010).

An interview typically starts with a short introduction to the study and a preamble about confidentiality, consent, and purpose. Building rapport with the participants before the interview and giving the participants plenty of time during the interview to consider and reflect on their issues help keep the interview atmosphere relaxed and open. The interviewer should attempt to use open-ended questions and not to direct the semi-structured interview. For example, asking closed questions or suggesting replies such as: "Has that been going on for a while?" is less successful than using open-ended prompts such as: "How long has this been going on for?" Interviewers should be trained in qualitative interviewing techniques. Such training also can help creating homogeneity in interview style when interviews are conducted 
across different sites or with different interviewers. Pilot interviews are an effective way to adjust the interview style as well as the topic guide.

A suitable length for a semi-structured open-ended interview varies depending on the participants' experiences with the topic and the competencies of the interviewer. Typically 1-2 hours of dialogue will allow the participants to summarize the accounts that they find significant and meaningful to the topic and the interviewer to ask more in-depth questions concerning specific aspects of their experiences. Conducting longer interviews (e.g., more than 2 hours) will not necessarily result in richer data.

Interviews are typically audio- or video-recorded, depending on the focus of the study. If the body language and the interaction between the researcher and the participant add significant meaning to the content of the interview, then videorecording should be favored. The researcher also can take notes of non-verbal behavior to complement audio-recordings. Audio- or video-recordings will typically be either transcribed verbatim or condensations of the content will be written to use for later analysis.

The biographic-narrative interview method (Wengraf, 2001) represents an alternative to semi-structured interviewing. In this iterative interview process several in-depth structured interviews are conducted with the same participant. Participants 
are typically invited to review and comment on the construction of storylines and thematic analysis that the researcher carries out (e.g., Lockey et al, 2010).

As mentioned above another type of interviewing used in qualitative research is focus groups (Krueger, 1988; Morgan, 1996). Compared to individual semi-structured interviews focus groups tend to compare and contrast individual experiences. Focus groups can be especially suitable when the participants are familiar with a phenomenon which might be difficult to discuss, for example because of taboos. In the group discussion different perspectives, common ground, or new opinions on the issue of research can be generated (Tye-Murray et al, 2009).

Other methods of data collection include field observations and participant diaries or documents (including photo or video diaries). When conducting field observations the data collection relies heavily on how the researcher in the field decides, or is lead by participants, to focus on details. Field observations also can be conducted with audio or video-recordings. In that case, the researchers must determine where, when, and for how long the recordings should be conducted. All of these decisions should be informed by the purpose of the research.

Using participant diaries or documents allows for both more or less structured and detailed data collection. The researcher can, for instance, create templates for the diaries with specific questions to fill in or they can be just blank pages that study participants fill out according to their own priorities. Diaries can help closely follow 
the perspectives of the participants over time. Other documents (e.g., newspapers, patient journals, or minutes of meetings) can be part of data collection when past events are examined.

Generally, data collection methods mentioned in this tutorial can be combined with all approaches of qualitative data analysis presented in this tutorial. In the case of conversational analysis, however, the data material should represent a natural setting of communication and the researcher should not take part as interviewer or moderator during data collection. Within this approach data collection involves audio- or video-recordings in order to allow a detailed communication analysis (Bryman, 2008).

\section{Data analysis}

In this section we describe qualitative data analysis within the four approaches which this tutorial focuses on. For a guide to all four approaches, see Table 2.

<Insert Table 2 about here.>

Coding, or the labelling of smaller parts of content (i.e., meaning units) which carries meaning in relation to the phenomenon studied, is relevant to all qualitative approaches. However, the abstraction level and focus of coding varies across the four approaches. This is described below. Common across the different approaches is also the initial task of becoming familiar with the data by listening to the 
interviews and/or reading the interview transcripts in order to get a sense of the data material as a whole. Also, it should be mentioned that for all types of qualitative data analysis the researchers' interests, will to some extent influence and guide the data analysis. Researchers should be aware of those and be transparent in their reporting.

Interpretative phenomenological analysis involves an inquiry of the collected data which begins by coding specific statements (Patton, 2002; Smith et al, 1999; Starks \& Brown Trinidad, 2007). The first step of coding in interpretative phenomenology is typically concrete and descriptive. A meaning unit reading: "I do quite a lot of driving about, you know, and I wear glasses... It's OK, but sometimes when I get out of the car for some reason or another, I whip my glasses off and my hearing aid goes flying." could be labeled with the code "I sometimes have trouble wearing my hearing aids in combination with glasses". The codes are further clustered by a focus on interpretations of what was experienced by participants and how it was experienced. A cluster that could come up in this context could for instance be called "hearing aids perceived as yet another technical device". Through a subjective and interpretative process the phenomenological researcher creates written distillations of the complex meaning making relevant to the clusters of codes. An interpretative phenomenological study does not test a theory or hypothesis, but it could develop and elaborate on an already established theory. Such development will then add the perspectives of the studied participants to the theory. Deep reflection is a strength of interpretative phenomenology, but it can be argued that the very flexible and 
interpretation-based approach of this method makes it less suitable for an collaborative interdisciplinary and multi-site study.

Within grounded theory the initially explorative, open, and iterative interview, coding, and analysis style gradually creates concepts and models which set the focus of the remaining interviews and the more and more selective type of coding (Charmaz \& Bryant, 2010; Strauss \& Corbin, 1998). In a later stage of a grounded theory study a meaning unit reading "I was at my daughter's birthday. I thought to myself "Oh, could we go home soon!" I realised that I had reached the point where I had to do something about my hearing problems." could be coded as "specific social event leading to trigger point." The final interviews serve to validate the concepts and models created throughout the analysis. Such iterative process requires that the data collection and analysis is carried out in a highly integrated and flexible manner. Grounded theory often is used to build models to describe social or psychological processes related to health or disability (Wallhagen, 2010). The method is well suited for open-ended research projects since conceptualization and model-building can develop in many different directions. On the other hand, the conceptual and theoretical focus of grounded theory might not always be suitable when aiming at gaining a broad descriptive presentation of the perceptions of people. On a practical level, the very collaborative and iterative analysis process used in grounded theory is suitable for a single-sited research group and can be difficult to suit multi-site international research. 
In qualitative content analysis, units of content are coded, creating as many concrete data driven codes as necessary to describe all aspects of the content (Elo \& Kyngäs, 2008; Graneheim \& Lundman, 2004; Hsieh \& Shannon, 2005). As in interpretative phenomenological analysis, the aim is to keep each code as close to the interview excerpts as possible. A typical level of abstraction for a code could be: "In the future, I will see whether some of the private firms are better." This code would for instance fit with a meaning unit reading: "Well in the future I'm going to jolly well take time and see them again and see if I could... Whether some of the private firms, where it costs a lot of money to get one, are better." The concrete data driven codes are later clustered in categories and the following process of describing and defining categories proceeds in an act of abstraction answering questions of what. The result of qualitative content analysis is typically a tree-structure of categories and codes. This tree-structure gives a comprehensive overview of the content of the data. The main advantage of qualitative content analysis is that it enables the qualitative researcher to get a data-driven and comprehensive overview of the whole data. Since qualitative content analysis is based on a systematically defined approach, it can also be suitable when conducting a multi-site study. On the other hand qualitative content analysis is a very time-consuming process. Furthermore, the outcome of qualitative content analysis will often be a broad descriptive representation of the data and will lack more in-depth interpretation. Although, when combining qualitative content analysis with thematic analysis, latent content is interpreted by a more fluent and intuitive process. Thematic analysis identifies themes by looking for recurring ideas and by searching for similarities or differences 
between participants' stories, meanings, and ways of making sense of specific issues relevant to them (Graneheim \& Lundman, 2004).

In conversational analysis the coding and condensation focuses on the use of language or on the interactions derived from language. For instance turn-taking can be an area of interest (Sacks et al, 1974). Turn-taking is the way conversation partners take turns in creating a dialogue. Varieties of length and content of sentences as well as the use of interruptions and pauses are coded, closely examined and compared between participants. Conversational analysis also can focus on the use of specific words. The coding process is usually informed by the focus of the study. For instance, if turn-taking is of relevance then the codes could for instance label the different ways of taking turns in the conversation. In such instance examples of codes could be "turn taking by contradiction" or "turn taking by confirmation." Conversational analysis is especially relevant when having a very specific topic (e.g., conversation repair) or hypothesis (e.g., social structures between clients and professionals) regarding the meaning of linguistic interaction in mind. On the other hand, when a study aims to explore the perceptions of people with a health condition (as for instance hearing impairment) conversational analysis might be too narrow and specific in scope. This section on conversational analysis describes the features relevant to a more qualitative version of conversational analysis. However, more quantitative versions of conversational analysis exist (Bryman, 2008). 
Four approaches to qualitative research have been described above and arguments for using each of them have been suggested. The philosophical convictions and theoretical knowledge of the researchers can influence the choice of qualitative methods and the data analysis itself. These convictions and knowledge should be made transparent when reporting qualitative results. Philosophical and theoretical influences should be acknowledged.

\section{$\underline{\text { Qualitative data management software }}$}

Qualitative data analysis can either be done with a pen and paper, in a word processor or with the help of qualitative data management software. Qualitative data management software such as NVivo (www.qsrinternational.com), atlas.ti (www.atlasti.com), or The Ethnograph (www.qualisresearch.com) can help manage parts of the data analysis. Software tools for qualitative data analysis are not designed to carry out data analysis on their own, but are rather tools to assist the researcher managing, coding, and sorting the data. More information on the different types of qualitative data management software is available at www.surrey.ac.uk/sociology/research/researchcentres/caqdas.

Condensation, coding, clustering, and modelling processes (e.g., as used in grounded theory) are all steps that can be carried out with the help of qualitative data management software. Interviews, audio-, or video-recordings can be imported into the software. Condensation can be made by selecting the material that fits the content areas of the study. For instance this could be all the content that answers to the question: "What do participants think/feel/do about hearing help-seeking and 
rehabilitation?" When all material that relates to the content areas is identified, the actual coding process can proceed. During the coding, sections of content are highlighted and identified with more or less concrete labels (see above section on data analysis). The software makes it easy to re-use codes if they appear to cover more than one section of content. When having created a number of codes, the clustering of codes is carried out using the software, which typically provides a helpful interface to group, label and overview the clusters created. See Appendix 1 for an example of a qualitative data management software interface.

The result of the data sorting process in the software can be a tree-structure that encompasses the total amount of content and gives an overview of the content of the data. Such a tree-structure can be informed by the concrete content of the data (as in qualitative content analysis) or by a more interpretational level of sorting the content (as in interpretative phenomenology analysis and grounded theory). When developing models and theories (e.g., in grounded theory), the software offers tools to build models by visually relating clusters of data and at the same time keeping the concrete content at close hand by links to the data files imported to the software. Another way to sort the data is by having already defined catalogues to sort the codes by. This method is suitable when a more deductive approach is used.

When a large amount of data is collected at several sites by several researchers, using a qualitative software data management program can have many advantages. It allows for consistency in the data handling and rapid sharing and merging of the 
work obtained in the distinct locations. Data management software generally gives the opportunity to treat a large amount of data by clustering, structuring, and creating models, while at the same time keeping the concrete content easily accessible. One potential caveat of qualitative data management software is that the software's functions and features may lead the analysis process instead of staying true to the study aims (Weitzman, 2000). For instance, investigating relations between data excerpts may not be as easy to complete in a qualitative data management software than if the analysis is performed on hard copies. It is therefore important that, before software is used, its role and applications are defined.

\section{Saturation and trustworthiness}

Achieving saturation means reaching the point of data satiety where no significant new data emerges within the specific type of sample (Morse, 1995). Saturation can be reached on different levels of abstraction, ranging from the level of concrete descriptions of situations and actions to a more theoretical saturation. Analyzing the data along with the data collection provides the opportunity to continuously add data to the analysis and thereby test whether codes, categories, or even more overarching definitions of themes or concepts keep fitting to the data.

Saturation can be determined in several ways. For example, when a sample seems to have reached saturation a test can be done by asking a researcher familiar with the research aim but not the current categorization to code part of the data and test 
whether the resulting codes lead to new significant categories or themes relevant to the research aim. If this happened it would be necessary to consider collecting more data in order to cover issues that had not been covered sufficiently by the already collected data.

In all four approaches described above, collaborative steps of coding, as well as reviewing the creations and definitions of codes, clusters, categories, themes, concepts, and conducting a saturation test are useful to ensure trustworthiness of the analysis.

\section{Special considerations for conducting international interdisciplinary qualitative research}

As the methodology and analysis of qualitative research is often iterative in nature, it is often conducted by researchers working closely together in the same discipline at the same study location. But arguments can be made for international and interdisciplinary research in audiology. Such collaborations will likely result in richer findings which may be applied more broadly.

\section{Rationale for international research in audiology}

The assessment and rehabilitation tools used for adults with hearing impairment are similar throughout the industrialized countries. For example, similar hearing tests, equipment, and hearing-aid manufacturers are used. On the other hand, the funding of hearing-aid provision, the type of professionals involved in the delivery of hearing 
help-seeking and rehabilitation vary between countries. Additionally, across countries, hearing aids may be provided by audiologists (with different educational backgrounds), hearing aid dispensers, or physicians (Goulios \& Patuzzi, 2008).

Since health experiences are influenced by contextual factors such as cultural norms (World Health Organization, 2001), it is likely that some aspects of hearing disability are not universal but rather vary regionally. In order to obtain data with international relevance, international studies should be considered.

Conducting an international multi-site study can raise both possibilities and significant challenges. Most qualitative data analysis is best suited for a research group situated at the same site, making it possible to have discussions and consensus building on a daily basis. The methodological consensus building that often is necessary when designing a qualitative study can require several discussions, rounds of peer-reviews, and adjustments before the method is carried out consistently between different sites. The last steps of the analysis, including categorization and conceptualization is in many cases most suitably conducted if carried out by two researchers working face to face. When conducting an international study where discussions and collaboration on a daily basis are not possible efforts should be made to structure activities and processes to ensure that all members of the group work in similar ways and with the same objectives in mind. Centralizing some activities (e.g., having one person in charge of the sampling) can be helpful. Tools for 
effective communication across sites such as teleconferences, e-mail, and secure web servers can also be very useful.

\section{Interdisciplinary research in Audiology}

When investigating health conditions with physiological, psycho-social, practical, and economic consequences, collaboration between several disciplines ensures that background, meanings, motives, reactions, and outcomes are assessed from many angles. Audiology has borrowed perspectives, knowledge, and skills from disciplines such as medicine, physiology, engineering, psychology, sociology, and pedagogy in order to better understand hearing disability and rehabilitation. Having researchers from different disciplines collaborating in all stages of a research project is common practice in audiology (e.g., Danermark et al, 2010; Kiessling et al, 2003). Such interdisciplinary approach is also relevant and fruitful when it comes to qualitative research regarding hearing disability and hearing rehabilitation.

Compromises between different cultures of research (biomedical vs. social science) and different professional relationships to study participants (clinician vs. nonclinician) have to be made during interdisciplinary collaboration (Cheek, 2008; Treloar \& Graham, 2003). The need for such compromises and considerations can foster fruitful in-depth discussions in many phases of the project and on various methodological issues.

\section{Summary and Conclusions}


Qualitative research can be a very fruitful way to gain a new, broader understanding of perspectives of people with hearing impairment. As any research methodology, however, it is important to consider that the approach has both benefits and limitations that should be weighed against each other.

The results of a qualitative study mirror the level of open-ended, semi-structured, and explorative design which is not aimed at quantitative objectives such as identifying predictors or specific relations between variables. This lack of ability to verify influences and associations between variables can be seen as a limitation of qualitative research. Another relevant critique of qualitative research is its inability to assure that study results are generalizable to a wide population of people with hearing impairment. Above all, qualitative data analysis can be much more time consuming than other forms of data analysis. Furthermore, the overall distribution of work in qualitative and quantitative research is quite different. Quantitative research especially is time intensive prior data collection whilst qualitative research is especially time intensive during and after data collection.

The benefits of the open-ended explorative design is that it can provide a deep understanding of experiences, intentions, and evaluations relevant to people with hearing impairment. Some aspects of living with hearing impairment that can be assumed to be paramount might be found to be of little importance to the participants, while on the other hand topics that have not been initially considered might emerge from the data (see Laplante-Lévesque et al, in press). 
This article describes methodological issues relevant to qualitative research in audiology. Different approaches have been described: grounded theory, interpretative phenomenological analysis, qualitative content analysis, and conversation analysis. The participant sampling strategy, data collection, and analytical process have been described to provide concrete examples of the implementation of qualitative research. Relevant differences between the four approaches presented have been illustrated in relation to the methodological steps described. It is hoped that this article will contribute to audiology research by helping those designing qualitative research projects or needing assistance in the interpretation of qualitative research.

\section{Acknowledgements}

The authors sincerely thank the Oticon Foundation for making this work possible. Marie Öberg provided a valuable contribution to the initial discussions that gave rise to this article.

\section{Declaration of interest}

The authors report no conflicts of interest. The authors alone are responsible for the content and writing of the article. 


\section{References}

Atkinson, P. \& Hammersley, M. 1994. Ethnography and participant observation. In: N.K. Denzin \& Y.S. Lincoln (eds.) Handbook of Qualitative Research. Thousand Oaks, CA: Sage, pp. 248-261.

Barry C.A., Britten, N., Barber, N., Bradley, C., Stevenson, F. 1999. Using reflexivity to optimize teamwork in qualitative research. Qual Health Res, 9, 26-44.

Beach, W.A., Easter, D.W., Good, J.S., Pigeron, E. 2005. Disclosing and responding to cancer "fears" during oncology interviews. Soc Sci Med, 60, 893-910.

Bentler, R.A. \& Kramer, S.E. 2000. Guidelines for choosing a self-report outcome measure. Ear Hear, 21, 37S-49S.

Berger, P. L. \& Luckmann, T. 1966. The Social Construction of Reality: A Treatise in the Sociology of Knowledge, Garden City, NY: Anchor Books.

Berntsen, D. \& Rubin, D.C. 2006. The centrality of event scale: A measure of integrating a trauma into one's identity and its relation to post-traumatic stress disorder symptoms. Behav Res Ther, 44, 219-231.

Bradley, E.H., Curry, L.A., Devers, K.J. 2007. Qualitative data analysis for health services research: Developing taxonomy, themes, and theory. Health Serv Res, 42, 1758-1772.

Braun, V. \& Clarke, V. 2006. Using thematic analysis in psychology. Qual Res Psychol, 3, 77-101.

Bryman, A. 2008. Social Research Methods ( $3^{\text {rd }}$ edition). Oxford, UK: Oxford University Press.

Carr, L.T. 1994. The strengths and weaknesses of quantitative and qualitative research: What method for nursing? J Adv Nurs, 20, 716-721. 
Carson, A. J. 2005. "What brings you here today?" The role of self-assessment in help-seeking for age-related hearing loss. J Aging Stud, 19, 185-200.

Charmaz , K. , 2000. Grounded theory: Objectivist and constructivist methods. In: N.K. Denzin \& Y.S. Lincoln (eds.) Handbook of Qualitative Research $\left(2^{\text {nd }}\right.$ edition). Thousand Oaks, CA: Sage, pp. 505-535.

Charmaz, K. \& Bryant, A. (eds.) 2010. The SAGE Handbook of Grounded Theory. London: Sage.

Cheek J., 2008. Researching collaboratively: Implications for qualitative research and researchers. Qual Health Res, 18, 1599-1603.

Collier, J.J. \& Collier, M. 1986. Visual Anthropology: Photography as a Research Method. Albuquerque, NM: University of New Mexico Press.

Côté, L. \& Turgeon, J. 2005. Appraising qualitative research articles in medicine and medical education. Med Teach, 27, 71-75.

Creswell, J. W. 2002. Educational Research: Planning, Conducting, and Evaluating Quantitative and Qualitative Research. Upper Saddle River, NJ: Pearson Education.

Creswell, J.W. 2003. Research Design: Qualitative, Quantitative and Mixed Methods Approaches ( $2^{\text {nd }}$ edition). Thousand Oaks, CA: Sage.

Danermark, B., Cieza, A., Gagné, J.-P., Gimigliano, F., Granberg, S. et al. 2010. International classification of functioning, disability, and health core sets for hearing loss: A discussion paper and invitation. Int J Audiol, 49, 256-262.

de Andrade, V. \& Ross, E. 2005. Beliefs and practices of Black South African traditional healers regarding hearing impairment. Int J Audiol, 44, 89-99.

Denzin, N.K. \& Lincoln, Y.S. (eds.) 2005. The SAGE Handbook of Qualitative Research $\left(3^{\text {rd }}\right.$ edition). Thousand Oaks, CA: Sage. 
DiCicco-Bloom, B. \& Crabtree, B.F. 2006. The qualitative research interview. Med Educ, 40, 314-321.

Dzurec, L.C. \& Abraham, I.L. 1993. The nature of inquiry: Linking quantitative and qualitative research. Adv Nurs Sci, 16, 73-79.

Elo, S. \& Kyngäs, H. 2008. The qualitative content analysis process. J Adv Nurs, 62, 107-115.

Goulios, H. \& Patuzzi, R.B. 2008. Audiology education and practice from an international perspective. Int J Audiol, 47, 647-664.

Golafshani, N. 2003. Understanding reliability and validity in qualitative research. Qual Rep, 8, 597-607.

Graneheim, U. H. \& Lundman, B. 2004. Qualitative content analysis in nursing research: Concepts, procedures and measures to achieve trustworthiness. Nurse Educ Today, 24, 105-112.

Hallberg, L. R.-M. \& Carlsson, S. G. 1991. A qualitative study of strategies for managing a hearing impairment. Br J Audiol, 25, 201-211.

Hétu, R., Riverin, N., Lalande, L., Getty, L., St-Cyr, C. 1988. Qualitative analysis of the handicap associated with occupational hearing loss. Br J Audiol, 22, 251-264.

Hodder, I. 2000. The interpretation of documents and material culture. In N.K. Denzin \& Y.S. Lincoln (eds.). Handbook of Qualitative Research $\left(2^{\text {nd }}\right.$ edition) Thousand Oaks, CA: Sage, pp. 703-715

Hsieh, H.F. \& Shannon, S.E. 2005. Three approaches to qualitative content analysis. Qual Health Res, 15, 1277-1288.

Inui, T.S. 1996. The virtue of qualitative and quantitative research. Ann Intern Med, $125,770-771$.

Kiessling, J., Pichora-Fuller, M. K., Gatehouse, S., Stephens, D., Arlinger, S. et al. 2003. 
Candidature for and delivery of audiological services: Special needs of older people. Int J Audiol, 42(Suppl. 2), 92-101.

Krueger, R.A. 1988. Focus Groups: A Practical Guide for Applied Research. Thousand Oaks, CA: Sage.

Kvale, S. 1996. Interviews: An Introduction to Qualitative Research Interviewing. Thousand Oaks, CA: Sage.

Kyngäs, H. 2004. Support network of adolescents with chronic disease: Adolescents' perspective. Nurs Health Sci, 6, 287-293.

Laplante-Lévesque, A., Pichora-Fuller, M.K., Gagné, J.-P. 2006. Providing an internetbased audiological counselling programme to new hearing aid users: $A$ qualitative study. Int J Audiol, 45, 697-706.

Laplante-Lévesque, A., Hickson, L., Worrall, L. 2010. Factors influencing rehabilitation decisions of adults with acquired hearing impairment. Int J Audiol, 49, 497507.

Laplante-Lévesque, A., Knudsen, L.V., Preminger, J.E., Jones, L., Nielsen, C. et al. in press. Hearing help-seeking and rehabilitation: Perspectives of adults with hearing impairment. Int J Audiol.

Lincoln, Y.S. 1992. Sympathetic connections between qualitative methods and health research. Qual Health Res, 2, 375-391.

Lincoln, Y.S. \& Guba, E.G. 1985. Naturalistic Inquiry. Beverly Hills, CA: Sage.

Lind, C., Hickson, L., Erber, N.P. 2006. Conversation repair and adult cochlear implantation: A qualitative case study. Cochlear Implants Int, 7, 33-48.

Lockey, K., Jennings, M.B., Shaw, L. 2010. Exploring hearing aid use in older women through narratives. Int J Audiol, 49, 542-549. 
Lopez, K.A. \& Willis, D.G. 2004. Descriptive versus interpretive phenomenology: Their contributions to nursing knowledge. Qual Health Res, 14, 726-735.

Mahoney, J. \& Goertz, G. 2006. A tale of two cultures: Contrasting quantitative and qualitative research. Pol Anal, 14, 227-249.

Miles, M.B. \& Huberman, A.M. 1994. Qualitative Data Analysis: An Expanded Sourcebook $\left(2^{\text {nd }}\right.$ edition). Thousand Oaks, CA: Sage.

Morgan, D.L. 1996. Focus Groups. Annu Rev Sociol, 22, 129-152.

Morse, J.M. 1995. The significance of saturation. Qual Health Res, 5, 147-149.

Morse, J.M. 2008. Confusing categories and themes. Qual Health Res, 18, 727-728.

Patton, M. 2002. Qualitative research and evaluation methods. 3rd ed. Thousand Oaks, CA: Sage Publications.

Poortinga, W., Bickerstaff, K, Langford, I., Niewöhner, J., Pidgeon, N.F. 2004. The British 2001 foot and mouth crisis: A comparative study of public risk perceptions, trust and beliefs about government policy in two communities. $J$ Risk Res, 7, 73-90.

Ryan, G.W. \& Bernard, H.R. 2003. Techniques to identify themes. Field Methods, 15, 85-109.

Sacks, H. 1995. Lectures on Conversation. Oxford, UK: Blackwell.

Sacks, H., Schegloff, E. A., Jefferson, G. 1974. A simplest systematics for the organization of turn-taking in conversation. Lang, 50, 696-735.

Sandelowski, M. 1995. Focus on qualitative methods: Sample size in qualitative research. Res Nurs Health, 18, 179-183.

Sandelowski, M. 2000. Focus on research methods: Whatever happened to 
qualitative description? Res Nurs Health, 23, 334-340.

Smith, J.A., Osborn, M., Jarman, M. 1999. Doing interpretative phenomenological analysis. In M. Murray \& K. Chamberlain (eds.) Qualitative Health Psychology: Theories and Methods. Thousand Oaks, CA: Sage, pp. 218-240.

Smith, J.A., Flowers, P., Larkin, M. 2009. Interpretative Phenomenological Analysis: Theory Method and Research. London: Sage.

Starks, H. \& Brown Trinidad, S. 2007. Choose your method: A comparison of phenomenology, discourse analysis, and grounded theory. Qual Health Res, $17,1372-1380$.

Strauss, A. L. \& Corbin, J. 1998. Basics of Qualitative Research: Techniques and Procedures for Developing Grounded Theory. Thousand Oaks, CA: Sage.

Scarinci, N., Worrall, L., Hickson, L. 2008. The effect of hearing impairment in older people on the spouse. Int J Audiol, 47, 141-151.

Southall, K., Gagné, J.-P., Jennings, M.B. 2010. Stigma: A negative and a positive influence on help-seeking for adults with acquired hearing loss. Int J Audiol, $49,804-814$.

Treloar, C. \& Graham, I.D. 2003. Multidisciplinary cross-national studies: A commentary on issues of collaboration, methodology, analysis, and publication. Qual Health Res, 13, 924-932.

Tye-Murray, N., Spry, J.L. \& Mauzé, E. 2009. Professionals with hearing loss: Maintaining that competitive edge. Ear Hear, 30, 475-484.

Vestergaard Knudsen, L., Öberg, M., Nielsen, C., Naylor, G., Kramer, S.E. 2010. Factors influencing help-seeking, hearing aid uptake, hearing aid use and satisfaction with hearing aids: A review of the literature. Trends Amplif, 14, 127-154.

Wallhagen, M.I. 2010. The stigma of hearing loss. Gerontologist, 50, 66-75. 
Weitzman, E. A. 2000. Software and qualitative research. In: N.K. Denzin \& Y.S. Lincoln (eds.) Handbook of Qualitative Research. Thousand Oaks, CA: Sage, pp. 803-820.

Wengraf, T. 2001. Qualitative Research Interviewing: Biographical Narratives and Semi-Structured Method. London: Sage.

World Health Organization. 2001. International Classification of Functioning, Disability, and Health. Geneva, Switzerland: World Health Organization. 
Table 1. Guide to differences between qualitative and quantitative research (refs: (Bryman, 2008; Carr, 1994; Mahoney \& Goertz, 2006).

\section{Qualitative}

Purposeful sampling

Smaller number of participants/observations

Sample size informed by saturation

Open-ended data collection to obtain naturalistic data coming from participants' own narratives or observations

In-depth engagement with and assimilation of the content of the data material informs the data analysis

\section{Quantitative}

Representative sampling

Larger sample

Sample size informed by power analysis

Structured and standardized data collection to obtain data on specific variables

Statistical analyses of numerical data informs the data analysis 
Table 2. Guide to qualitative approaches used within health research (refs: Bryman, 2008; Graneheim \& Lundman, 2004; Miles \& Huberman, 1994; Smith et al, 1999).

\begin{tabular}{|c|c|c|c|c|c|}
\hline & $\begin{array}{l}\text { Developed } \\
\text { within field }\end{array}$ & $\begin{array}{l}\text { Purpose of } \\
\text { method }\end{array}$ & Analysis & Data collection & $\begin{array}{l}\text { Study examples within } \\
\text { health research }\end{array}$ \\
\hline $\begin{array}{l}\text { Interpretative } \\
\text { phenomenolo- } \\
\text { gical analysis }\end{array}$ & $\begin{array}{l}\text { Philosophy } \\
\text { and } \\
\text { psychology }\end{array}$ & $\begin{array}{l}\text { Describe/inter- } \\
\text { pret how study } \\
\text { participants } \\
\text { perceive the } \\
\text { meaning of a } \\
\text { lived } \\
\text { experience } \\
\text { related to a } \\
\text { specific } \\
\text { phenomenon. }\end{array}$ & $\begin{array}{l}\text { Codes, categories } \\
\text { and themes are } \\
\text { created with focus } \\
\text { on experience and } \\
\text { meaning-making. } \\
\text { Descriptive wrt } \\
\text { experiences. } \\
\text { Interpretative wrt } \\
\text { meaning-making. } \\
\text { Inductive approach. }\end{array}$ & $\begin{array}{l}\text { Primarily semi- } \\
\text { structured interviews, } \\
\text { but also postal } \\
\text { questionnaires, e-mail } \\
\text { dialogue, focus groups, } \\
\text { etc. } \\
\text { The productive dialogue } \\
\text { between researcher and } \\
\text { study participant is } \\
\text { acknowledged. }\end{array}$ & $\begin{array}{l}\text { Hétu et al, } 1988 \text { (disability } \\
\text { associated with noise- } \\
\text { induced hearing impairment) } \\
\text { Lockey et al, } 2010 \text { (hearing } \\
\text { aid use among older women) }\end{array}$ \\
\hline $\begin{array}{l}\text { Grounded } \\
\text { theory }\end{array}$ & Sociology & $\begin{array}{l}\text { Develop } \\
\text { model/concept/ } \\
\text { theory of a } \\
\text { specific } \\
\text { psychological or } \\
\text { social process. }\end{array}$ & $\begin{array}{l}\text { Codes, categories } \\
\text { and models are } \\
\text { created and } \\
\text { gradually } \\
\text { conceptualised } \\
\text { through a process of } \\
\text { constant } \\
\text { comparison carried } \\
\text { out in parallel with } \\
\text { data collection. } \\
\text { Inductive approach. }\end{array}$ & $\begin{array}{l}\text { Everything relevant to } \\
\text { the topic can be } \\
\text { considered as data: } \\
\text { semi-structured } \\
\text { interviews, focus groups, } \\
\text { informal talks, } \\
\text { newspapers, previous } \\
\text { knowledge, } \\
\text { observations, } \\
\text { documents, quantitative } \\
\text { data, etc. }\end{array}$ & $\begin{array}{l}\text { Carson, } 2005 \text { (role of self- } \\
\text { assessment in help-seeking } \\
\text { for age-related hearing } \\
\text { impairment) } \\
\text { Hallberg \& Carlsson, } 1991 \\
\text { (managing a hearing } \\
\text { impairment) } \\
\text { Laplante-Lévesque et al, } \\
2006 \text { (internet-based } \\
\text { counselling of new hearing } \\
\text { aid users) }\end{array}$ \\
\hline $\begin{array}{l}\text { Qualitative } \\
\text { content } \\
\text { analysis }\end{array}$ & $\begin{array}{l}\text { Ethnography, } \\
\text { qualitative } \\
\text { sociology, and } \\
\text { psychology }\end{array}$ & $\begin{array}{l}\text { Describe } \\
\text { meaning, } \\
\text { intentions, } \\
\text { consequences } \\
\text { and context } \\
\text { connected to a } \\
\text { specific } \\
\text { phenomenon. }\end{array}$ & $\begin{array}{l}\text { Codes, categories } \\
\text { and themes are } \\
\text { created with focus } \\
\text { determined by } \\
\text { research question. } \\
\text { Inductive or } \\
\text { deductive approach. }\end{array}$ & $\begin{array}{l}\text { Data from semi- } \\
\text { structured interviews, } \\
\text { focus groups, narratives, } \\
\text { diaries, observations, } \\
\text { documents, etc. }\end{array}$ & $\begin{array}{l}\text { Kyngäs, } 2004 \text { (support } \\
\text { network of adolescents with } \\
\text { a chronic disease from the } \\
\text { patient's perspective) } \\
\text { Laplante-Lévesque et al, } \\
2010 \text { (factors influencing } \\
\text { intervention decisions) }\end{array}$ \\
\hline $\begin{array}{l}\text { Conversation } \\
\text { analysis }\end{array}$ & $\begin{array}{l}\text { Ethno- } \\
\text { methodology, } \\
\text { qualitative } \\
\text { psychology, } \\
\text { and sociology }\end{array}$ & $\begin{array}{l}\text { Describing } \\
\text { linguistic } \\
\text { interaction and } \\
\text { how it creates } \\
\text { patterns of } \\
\text { social life in a } \\
\text { specific } \\
\text { situation. }\end{array}$ & $\begin{array}{l}\text { Analysis of detailed } \\
\text { transcriptions of } \\
\text { conversation. Often } \\
\text { with focus on } \\
\text { characteristics of } \\
\text { conversation rather } \\
\text { than its content. } \\
\text { Inductive or } \\
\text { deductive approach. }\end{array}$ & $\begin{array}{l}\text { Audio- or video } \\
\text { recording of } \\
\text { conversation in natural } \\
\text { occurring social } \\
\text { situations. }\end{array}$ & $\begin{array}{l}\text { Beach et al, } 2005 \text { (patient- } \\
\text { doctor conversation } \\
\text { concerning fear about } \\
\text { cancer) } \\
\text { Lind et al, } 2006 \text { (cochlear } \\
\text { implants and conversation } \\
\text { repair) }\end{array}$ \\
\hline
\end{tabular}


Appendix 1. The Nvivo (www.qsrinternational.com) working interface. The bottom left panel is the original interview transcription and the bottom right panel shows the codes as they are assigned to data sections.

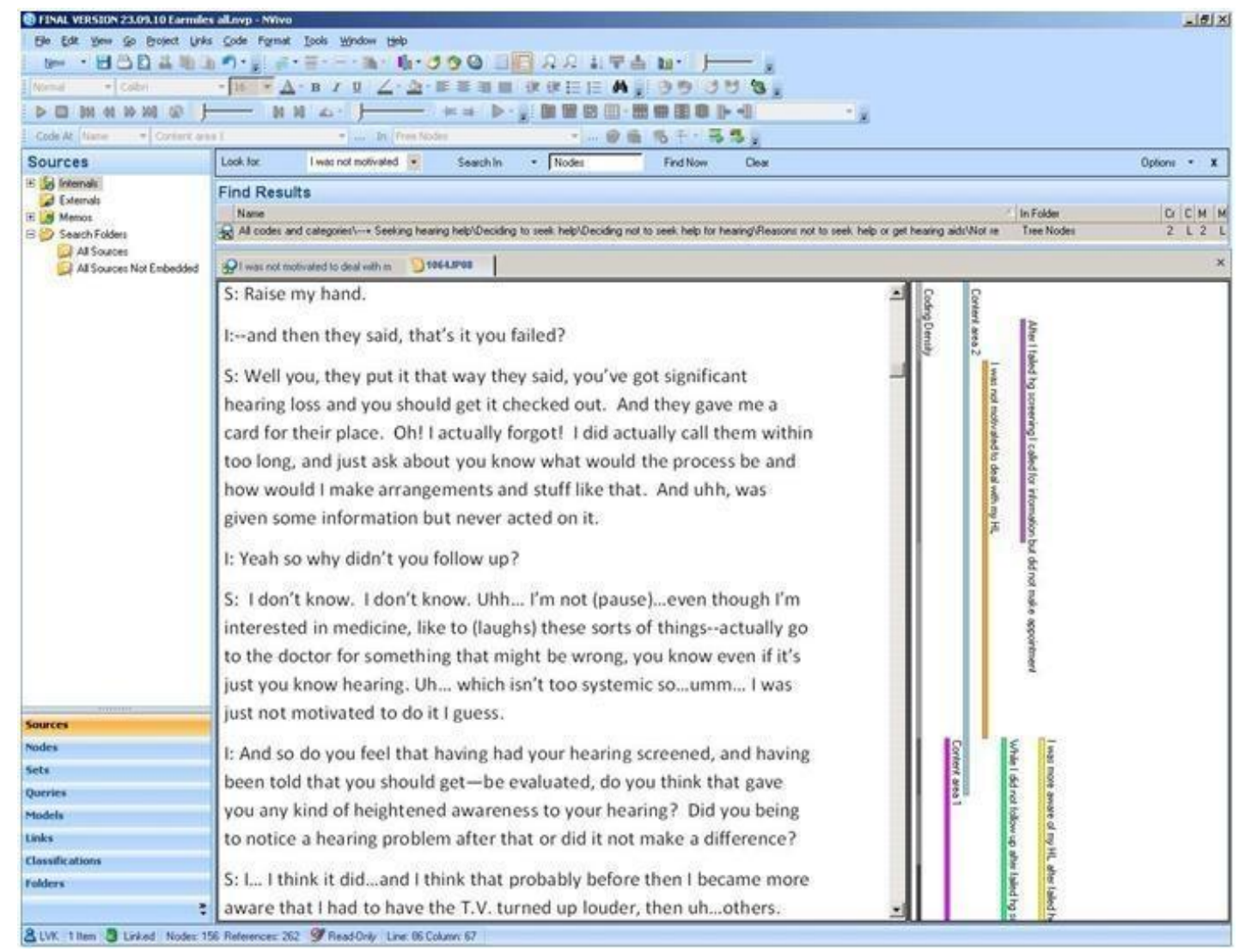

